\title{
Research on Music Therapy to Promote Health and Well-being of General Population
}

\author{
Yanan $\mathrm{Zhu}^{*}$ \\ School of Music \\ Tonghua Normal University \\ Tonghua, China \\ E-mail:*dbcy9999@163.com
}

\begin{abstract}
Music therapy is one of the health promotion practices that can advance wellness. The holistic view proposes an integrated approach to health and wellness in which body, mind, and spirit are seen as integrated parts of the whole system. Holistic medicine treats the whole person (body, mind, and spirit), not just the symptoms or disease, but encourages individuals to take responsibility for their own health and stresses self-care, self-help, prevention, and strive for optimum wellness and balance in all areas of life. Holistic practices focus on the individuals and further encourage them to promote their potential, self-awareness, and growth through finding their own internal answers.
\end{abstract}

Keywords-Music Therapy; Health; General Population; Relaxation

\section{INTRODUCTION}

In recent decades, increased awareness of and interest in holistic medicine and alternative healing practices also have helped focus the public's attention not just on curing disease but on striving for and maintaining optimum wellness by "adopting a life style that focuses on health". In 1926, Jon Christian Smuts, a South African philosopher, introduced the concept of "holism." Medical science had become increasingly concerned with under- standing disease from analytic studies of smaller physiological components. Gordon states that "holistic (sometimes spelled wholistic) medicine has come to denote both an approach to the whole person in his or her total environment and a variety of healing and health promoting practices."

In a narrow sense, health often is defined as the absence of disease, infir-mity, or abnormality. However, in recent decades, the concept of health has expanded so that mere absence of disease alone does not necessarily constitute health. Creagan observes that good health encompasses mental and emotional as well as physical attributes; an optimistic attitude and continued connections with family, friends, and community are especially important [1]. In the broad sense, then, one may define health or wellness as a state of optimal functioning and complete mental, physical, spiritual, and social well-being. Others view health not as an all-or-nothing state of wellness or illness, but as something that exists on a continuum from optimum health to sub optimal health to overt illness or disability to approaching death to death. Most people move back and forth along this continuum throughout their lives, although they are always striving to maintain optimum health. In general, the task of medical professionals, then, is to help individuals maintain good health, provide information and procedures related to preventing disease, and cure those who become ill as quickly as possible [2].

The increased emphasis on health and wellness in recent years has led members of the medical community to focus more on preventative medicine, which strives to help individuals maintain optimum health. From the preventative point of view [3]'good medical care acts on a person's health rather than reacting to a person's health problems". Follow-up care provided to an individual after acute medical treatment also may be considered part of wellness or preventative services, for this follow-up care aims to help an individual achieve and maintain the highest possible degree of health and independent functioning. Follow-up care Health and Well-Being in the General Population 587 may involve problems with following a prescribed regimen and adapting to new constraints [4].

Convincing Basically healthy people in the general population may need to find lifestyles that will help them maintain optimum health and independent functioning. General needs often include maintaining healthy diet and exercise regimens; having adequate social, emotional, and spiritual support systems; developing coping strategies and creative problem-solving techniques to weather difficult times; finding ways to manage stress and relieve frustration; and having outlets for creative or emotional expression. According to Maslow [5], when more basic needs (e.g., food and shelter, safety, love and nothingness, self-esteem) are met, individuals strive for self-actualization and the full realization of all their potentialities. Some individuals in the general population, therefore, seek tools for personal growth and increased self-awareness and personal fulfillment. Many individuals also desire experiences that add meaning, joy, or beauty to their lives. Montello discusses music and sound and presents techniques of relaxation to lead to personal growth and wellness. This paper provides examples and specific exercises for relaxation [6]. 


\section{SETTINGS For SERVICE DELIVERY}

Health and wellness programs and services for the general public exist in various settings, including hospitalsponsored programs, community health fairs, park and recreation programs, workshops and seminars, fitness centers, wellness centers, stress reduction clinics, schools or community colleges, corporate wellness programs, churches, and community centers. Individual service providers working in private practice may contract their services to individuals or groups. Music therapists could work in any of these settings by providing direct or consultant services and by working with clients as individuals or in groups . In addition, music therapists may provide services through music stores or studios or in private practice settings.

\section{HOW MUSIC IS USED IN THERAPY}

One of the pioneers of music therapy, Willem van de Wall, advocated using music for wellness as early as the 1930s. Van de Wall believed that music not only could provide aesthetic satisfaction for adults in the general population but also enhance "muscle relaxation, emotional expression, and relief from routine, which could lead to increased efficiency when responsibilities were resumed". In recent years, music therapists have given increasing attention to ways they can expand their services beyond the institutional setting and clients with disabilities to also promote health and wellness in the general population" Wellness components of social integration, emotional health and spirituality are also meaningfully addressed through music therapy." The use of music as preventative medicine and as a strengthener of health and character made a resurgence in the United States in the latter part of the twentieth century. The holistic health movement, focusing on interdependence of body, mind, and spirit for maintaining health and well-being, generated interest in ancient healing practices using music and in contemporary ways to use music to facilitate healing, relaxation, centering, stress reduction, emotional release, consciousness expansion, and the highest possible state of well-being . The therapeutic use of music has moved into board rooms and wellness programs of businesses, hospitals, and major corporations as employers recognize the need to reduce stress, alleviate staff burnout, promote wellness, and inspire innovative and effective ways to encourage team work and enhance creativity. The medical community also is beginning to recognize the important role music and the arts can play in preventative care and health maintenance. For example, medical doctors Itoh and Lee observe: If food is a nutrient for the body, music is for the mind. . . . As music is closely related to human well-being, it does have therapeutic value. In the total concept of health care, music therapy should be recognized as another modality for Prevention and Health Promotion. Music educators, too, are beginning to recognize music's lifelong health benefits and are finding ways to help people enjoy music throughout their lives Woolrich point out: "Children should be made aware of the long-term impact their health-related decisions have on their lives and the importance of maintaining a healthy lifestyle in order to avoid health problems later in life." With its ability to structure order out of chaos and be a transcendent event (Crowe 1991; Spencer 1978), music can "match an individual's level of func- tioning whatever it may be and help the person move toward the wholeness of healing" . Music is also a natural vehicle for addressing the whole person (body, mind, and spirit). Since "people can enjoy participating in music at every stage of life", music can be an important tool for promoting wellness and channeling creativity productively in the general population with individuals of all ages. Furthermore, Kenny has argued that "even though music may not be the natural vehicle for everyone's creativity, it can be an experimental ground in which to try out creative processes and apply them through a powerful medium."Music experiences can help individuals in the general population maintain health and well-being in many ways. Sometimes, individuals may use music in therapeutic or beneficial ways for themselves, as when they listen to certain types of music to relax or lift their spirits, when they listen to music while exercising, or when they play musical instruments to relieve tension. While beneficial, this is not true music therapy, because it does not have the interaction among therapist, client, and music At other times, music experiences will be more beneficial if they are structured by and performed under the direction or supervision of a trained music therapist, who bases interventions on an assessment of the unique needs of the particular individual or individuals and adapts programs to their specific responses.

People who wish to use music to increase their total health must realize that sound and music can have both positive and negative effects . In addition, certain experiences, like Guided Imagery and Music , may arouse painful issues that are best addressed under the guidance of a trained therapist. The next sections of this paper provide some examples of music experiences that can facilitate relaxation, reduce stress, decrease isolation, facilitate cooperative interactions, improve coping and problemsolving abilities, promote healthy habits and behaviors, humanize the environment, expand consciousness, and increase personal transcendent event awareness . All these experiences can play a role in helping people in the general population reach a state of optimal functioning and complete mental, physical, and social well-being.

\section{MUSIC EXPERIENCES FOR RELAXATION AND STRESS REDUCTION}

The "most widely accepted application of music as a therapeutic agent" throughout history has been "its use as a calming agent to combat anxiety, tension, and stress." Based on work by Bernar and Krupat, Burns et al. report that stress is based on three main elements: "the external stimuli, the internal response, and the interaction between the two." When the goal is to promote relaxation, the music therapist faces complex choices about the best music for an 
individual client. After investigating the characteristics of relaxing music used for anxiety control, Elliott, the most desirable characteristics of music for relaxation. The components they consider, in descending order of importance, are "tempo, melody, beat, harmony, rhythm, complexity, key, scale, articulation, interval, melodic range, voice, instrumentation, dynamics, and character". For each of these, they describe relaxing and non-relaxing characteristics. Many of these same music-mediated relaxation and stress reduction techniques will work very well for most people in the general population. One aspect of relaxing music that has received attention from several researchers is its complexity. According to Walker's 1980 "hedgehog" theory ("so named because the theory has one explanation for many situations, just as the spiny little European animal rolls into a ball in response to many stimuli" the closer a musical stimulus is to the optimal complexity level, the greater is the preference for that structure. Preferred music usually is related to greater response in music therapy research. For example, Heyduk rates preference of musical compositions as it relates to complexity and exposure frequency. Radocy and Boyle discuss the relationship between preference and complexity: "Although optimal complexity levels vary among and within individuals, each individual has an optimal complexity level for a stimulus class at any particular time." Crowe wrote the paper Music and Soul making: Toward a New Theory of Music Therapy from the perspective of complexity science, which provides a more inclusive paradigm that allows her to go beyond the traditional, research-based perspective and discuss music's effect on the total person in the therapeutic setting. She says, "The theory of music and soul making is based on the contention that music is a fundamental, holistic experience that impacts functioning in all areas - body, mind, emotion and spirit". She writes of music therapy as a process which leads to achievement of higher potential.

\section{MUSIC EXPERIENCES TO DECREASE ISOLATION AND FACILITATE COOPERATIVE INTERACTIONS}

Since prehistoric times, people have gathered in groups to create and share music as together they experience its energy and spirit. Group music experiences that are prevalent in society today can decrease isolation by giving people reasons for assembling in groups: to listen, to attend concerts, to practice or perform, to dance, to learn, and to discuss . Throughout life, music experiences can offer people many opportunities for positive interactions with others and for volunteer opportunities that research shows are vital components of good health. Especially as they actively make music together, people find they "are not singular, isolated units, but rather an interrelated web of unified beings whose purpose is to work together as one". Thus, interesting and meaningful non-threatening group music experiences can turn indifference and isolation into interest and involvement. One demonstrators how gifted students, who were isolated, vulnerable, and interacted poorly with others, learn to work together cooperatively, share ideas and feelings, and improve their self-concept through music therapy experiences using GIM andOrffSchulwerk techniques. Another study showed that group singing increased trust and cooperation among group members significantly more than music listening, games, or film viewing.

\section{MUSIC EXPERIENCES TO IMPROVE COPING STRATEGIES AND PROBLEM-SOLVING SKILLS}

In the mid-1930s, Willem van de Wall, one of music therapy's early pioneers in the United States, "spoke of music as a means for adults to be physically, mentally, and culturally developed despite the ever-increasing burdens of life". Throughout history, people have used songs and music to help lift their spirits and cope with difficult life situations. Even today, involvement in various kinds of music experiences (singing, playing, listening, moving, and creating) can help people experience beauty, joy, personal satisfaction, and meaning that lifts them, at least for a time, above and beyond their not-so-pleasant life situations. Studies show that "at-risk" children and adolescents often respond more positively to music experiences than to verbal interventions or traditional teaching methods. For all people, participation in structured singing, instrumental, listening, movement-to-music, or improvisation/composition experiences can stimulate creativity; help sustain a sense of wonder and curiosity (something people often lose after childhood); lead people to see problems in new ways and find innovative solutions; and give people courage to improvise, experiment, explore alternatives, and try different things. Even major corporations now use music experiences such as drum circles to help increase creative problem solving, break preexisting molds and barriers, and facilitate innovative thinking. Music therapists have found that music therapy experiences can be effective crisis intervention and prevention techniques. For example, having individuals improvise music that expresses feelings or conflicts about an anticipated or recently experienced traumatic event may help them maintain or regain an accurate reality perspective, while shared group music experiences (e.g., active listening and discussion, singing, group improvisations) can provide needed support from others. In addition, structured experiences involving lyric analysis, song writing, improvisation, and music-assisted guided imagery Health and Well-Being in the General Population 597 may (a) assist with cognitive and emotional processing of the crisis event, (b) lead individuals to discover alternative solutions or responses, (c) help individuals find new ways of coping, (d) increase identification and awareness of inner strengths, and (e) facilitate internalizing affirmative messages. Governments, too, are recognizing music's power to help people cope with difficult situations. For example, during the 1991 Persian Gulf War, the Israeli Broadcasting Authority intentionally used music to help its citizens cope with the crisis by playing songs stressing strength and national unity, using parodies of popular tunes to give 
specific instructions for safety and defense preparations, and broadcasting soothing, nostalgic music during attacks to help reduce fear and anxiety. During the war, only Hebrew songs were broadcast, and special children's music was played in the evening to help the children cope with the stress and trauma of the situation. In these ways, "through mass communication, the power of music was used to assist the entire population in developing more adaptive coping methods, which included instilling feelings of national unity and establishing support systems".

\section{Music EXPERIENCES TO PROMOTE HeAlThY HABITS AND BEHAVIORS}

As many people strive for improved health and wellbeing, they know the things they should do but have difficulty making these things a regular part of their lives. Exercise, for example, often is perceived as boring and tedious. Adding music, however, may make exercise more enjoyable and provide the needed motivation for people to participate in and sustain exercise studied factors associated with exercise enjoy- ment among 282 female aerobic dance students with a mean age of 21.06 years: "Satisfaction with the music was the best predictor of exercise enjoy- ment accounting for $21 \%$ of the variance" . Other factors considered were satisfaction with the instructor and role identity. Tempo/beat and intensity/ loudness were found to be the most important musical characteristics in the exercise class. Because exercise enjoyment relates to frequency and regularity in participation in exercise classes, it is an important consideration in a wellness program. According to NASA, music can promote compliance with exercise routines, decrease the tedium of repeated movements, and help individuals attain the desired level of intensity found that music helped young adults increase their motivation, pacing, strength, and endurance during aerobic activities. Beckett reported that individuals who listened to music walk farther and with less effort than when they exercised without music. Other research concludes that people who listen to music during exercise perceive the exercise as less stressful.

Moreover, music with phrases and tempos that correspond to those of the physical movement can facilitate muscle coordination and rhythmic movement. As Thaut remarks, "The tempo of the music is adjusted to accommodate the subject's baseline gait capabilities and then incrementally increased as gait performance improves." In fact, many cultures historically have used marching songs and work songs to decrease fatigue, increase rhythmicity and fluidity of movement, and help lessen injury. The music best facilitates exercise when it (a) matches the exercising person's individual preferences, (b) provides appropriate rhythmic and structural sup- port for the movement, and (c) evokes pleasant associations.

\section{CONCLUSION}

However, just as consumers/clients seek the help of trained physicians for more severe problems, for guidance in using over-the-counter medications and remedies, or for help when nonprescription medications or home remedies are not effective, they must also learn to seek the help of trained music therapists when commercially available music materials or self-prescribed music programs or activities no longer have the desired effects. As they seek to move into the mainstream of wellness services, music therapists must take the lead in educating consumers about the entire spectrum of music and wellness treatments and help individuals identify which treatments may be most beneficial for their personal use at particular times or for particular purposes. Music therapists also must help the general public develop guidelines for when they can safely "self-fulfilment," when they might need to consult with a professional music therapist, and when they might need the direct services of a professional music therapist to help them reach their desired goals for improving their total health and quality of life. Finally, music therapists must be able to support their claims for music's preventative, health maintenance, and health enhancement effects with solid scientific research. Then music therapy will be able to find a place as an important part of wellness/preventative medicine services, as well as rehabilitative services, and as a vital service for the general population as well as for disabled individuals. Krout hopes that "consumers, creative arts therapists, and other allied health professionals may be better educated as to the physiological effects of music listening as they relate to facilitating relaxation as part of an ongoing wellness initiative and lifestyle."

\section{ACKNOWLEDGMENT}

This research was financially supported by Research Foundation of Education Bureau of Jilin Province (Grant No.2016238 and Grant No.JJKH20180860KJ).

\section{REFERENCES}

[1] Ghetti, C. M., Hama, M., \& Woolrich, J, Music therapy in wellness. In A-A. Darrow, Introduction to approaches in music therapy, American Music Therapy Association, 2008, pp. 131-151.

[2] Hanser, S. B. \& Mandel, S. E, Manage your stress and pain through music, Berkley Press, 2010

[3] Brain Injury, Retrieved, http://www.braininjury.com/injured.shtml, 2005

[4] Montello, L, Essential musical intelligence: Using music as your path to healing, creativity, and radiant wholeness, Quest Books Theosophical Publishing House, 2002

[5] Codding, P. A, A comprehensive survey of music therapists practicing in correctional psychiatry: Demographics, conditions of employment, service provision, assessment, therapeutic objectives, and related values of the therapist. Music Therapy Perspectives, 23(2), 2002, pp. 56-68.

[6] Deanna Marcum, Library Leadership for the Digital Age, Information Services \& Use 36, no. 1-2, 2016, pp. 105-111. 